\title{
Analysis of the $\mathbf{N}$-terminal binding domain of $\mathbf{G}_{0} \alpha$
}

\author{
Liliana BUSCONI ${ }^{1}$ and Bradley M. DENKER ${ }^{2}$ \\ Renal Division, Brigham and Women's Hospital and Harvard Medical School, 75 Francis St., Boston, MA 02115, U.S.A.
}

Signalling from membrane receptors through heterotrimeric G-proteins $(\mathrm{G} \alpha$ and $\mathrm{G} \beta \gamma)$ to intracellular effectors is a highly regulated process. Receptor activation causes exchange of GTP for $\mathrm{GDP}$ on $\mathrm{G} \alpha$ and dissociation of $\mathrm{G} \alpha$ from $\mathrm{G} \beta \gamma$. Both subunits remain membrane-associated and interact with a series of other molecules throughout the cycle of activation. The N-terminal binding domain of $\mathrm{G} \alpha$ subunits interacts with the membrane by several partially defined mechanisms: the anchoring of $\mathrm{G} \alpha$ to the more hydrophobic $\mathrm{G} \beta \gamma$ subunits, the interaction of $\mathrm{N}$-terminal lipids (palmitate and/or myristate) with the membrane, and attachment of amino acid regions to the membrane amino acids 11-14 of $\mathrm{G}_{0} \alpha$ (D[11-14]); Busconi, Boutin and Denker (1997) Biochem. J. 323, 239-244\}. We characterized N-terminal mutants of $\mathrm{G}_{0} \alpha$ with known $\mathrm{G} \beta \gamma$-binding properties for the ability to interact with phospholipid vesicles and membranes prepared from cultured cells (acceptor membranes). In vitro analysis allows membrane interactions that are important to the activated and depalmitoylated state of $\mathrm{G} \alpha$ to be characterized. Subcellular localization was also determined in transiently transfected COS cells. All of the mutant proteins are myristoylated, and differences in myristoylation do not account for changes in membrane binding. Disrupting the $\mathrm{N}$-terminal $\alpha$-helix of $\mathrm{G}_{0} \alpha$ with a proline point mutation at Arg-9 (R9P) does not affect interactions with $\mathrm{G} \beta \gamma$ on sucrose-density gradients but significantly reduces acceptor membrane binding. Deletion of amino acids 6-15 (D[6-15]; reduced $\mathrm{G} \beta \gamma$ binding) or deletion of amino acids 3-21 (D[3-21]); no detectable $\mathrm{G} \beta \gamma$ binding) further reduces acceptor membrane binding. When expressed in COS cells, R9P and $D[6-15]$ are localized in the membrane similar to wild-type $G_{0} \alpha$ as a result of the contribution from palmitoylation. In contrast, $\mathrm{D}[3-21]$ is completely soluble in COS cells, and no palmitoylation is detected. The binding of $\mathrm{G}_{0} \alpha$ and mutants translated in vitro to liposomes indicates that $\mathrm{G}_{0} \propto$ preferentially binds to neutral phospholipids (phosphatidylcholine). R9P and D[11-14] bind to phosphatidylcholine liposomes like $\mathrm{G}_{0} \alpha$, but $\mathrm{D}[6-15]$ exhibits no detectable binding. Taken together, these studies suggest that interactions of the $\mathrm{N}$-terminus of $\mathrm{G} \alpha$ subunits with the membrane may be affected by both membrane proteins and lipids. A detailed understanding of $\mathrm{G} \alpha$-membrane interactions may reveal unique mechanisms for regulating signal transduction.

\section{INTRODUCTION}

Heterotrimeric G-proteins, composed of $\mathrm{G} \alpha$ and $\mathrm{G} \beta \gamma$ subunits, reside in the inner leaflet of the plasma membrane where they function as critical intermediate signalling molecules between transmembrane receptors and intracellular effector molecules. Hormone receptor activation causes release of GDP from $\mathrm{G} \alpha$, allowing GTP to bind. $\mathrm{G} \alpha$ and $\mathrm{G} \beta \gamma$ dissociate, and both subunits remain activated until the intrinsic GTPase activity of $\mathrm{G} \alpha$ hydrolyses GTP to GDP. Throughout the cycle of activation, Gproteins remain membrane-associated and participate in multiple transient protein interactions (reviewed in [1-3]).

Several lines of evidence reveal that the N-terminal region of $\mathrm{G} \alpha$ subunits functions, in part, as a membrane-binding domain (reviewed in [4]). The site(s) for lipid modifications of $\mathrm{G} \alpha$ with myristate and/or palmitate occur within the first 10 amino acids of most $\mathrm{G} \alpha$ subunits. Blocking lipid modifications of $\mathrm{G} \alpha$ subunits in transfected COS cells by point mutations causes significant reductions in membrane attachment (reviewed in [4]). Analysis of crystal structures of $\mathrm{G} \alpha \beta \gamma$ heterotrimers reveals that the $\mathrm{N}$ terminus of $\mathrm{G} \alpha$ and the prenylated C-terminus of $\gamma$ (required for membrane attachment of $\mathrm{G} \beta \gamma$ ) are in close proximity and predicted to face the plasma membrane [5,6]. $\mathrm{G} \alpha$ interactions with the more hydrophobic $\mathrm{G} \beta \gamma$ subunits may also stabilize $\mathrm{G} \alpha$ in the membrane [7], and we recently demonstrated that an amino acid region in the $\mathrm{N}$-terminus of $\mathrm{G}_{0} \alpha$ provides additional membrane anchoring [8].

Despite some details of $\mathrm{G} \alpha \mathrm{N}$-terminal structure from crystal structures, our understanding is incomplete. All crystallized Gproteins obtained thus far are without lipid modifications and the N-terminal conformation is dynamic. With guanosine $5^{\prime}-[\gamma-$ thio]triphosphate (GTP[S]) bound to $\mathrm{G} \alpha$, the $\mathrm{N}$-terminus is disordered. However, a compact $\alpha$-helical domain exists in the GDP-bound form, and an extended $\alpha$-helix contacts G $\beta \gamma$ in the heterotrimer [5,9-11]. The effect of lipid modification(s) on $\mathrm{N}$ terminal structure is unknown, and lipid modifications vary among $\mathrm{G} \alpha$ subunits. In addition, the N-termini of $\mathrm{G} \alpha$ subunit families vary in amino acid composition and length. (On the basis of number of amino acids from the $\mathrm{N}$-terminus to the completely conserved LLLLGAGE region that comprises part of phosphatebinding pocket, the $\mathrm{N}$-terminal amino acid lengths are: $\mathrm{G}_{\mathrm{s}} \alpha, 42$; $\mathrm{G}_{\mathrm{i}} \alpha_{2}, 34 ; \mathrm{G}_{\mathrm{t}} \alpha, 30 ; \mathrm{G}_{\mathrm{q}} \alpha, 35 ; \mathrm{G}_{12} \alpha$, 56.) Taken together, these observations suggest that multiple features within the $\mathrm{N}$-termini are likely to be important for membrane attachment. The differences in $\mathrm{N}$-terminal structure among $\mathrm{G} \alpha$ subunit families may be important for membrane and protein interactions that affect signal transduction and specificity.

In this study, we have segregated some of the variables important to the mechanisms of membrane attachment for the pertussis toxin family member, $\mathrm{G}_{0} \alpha$. Utilizing a series of $\mathrm{N}$ -

Abbreviations used: GTPS[S], guanosine 5'-[ $\gamma$-thio]triphosphate; DTT, dithiothreitol; BMH, 1,6-bis(maleimido)hexane; PC, phosphatidylcholine; PS, phosphatidylserine; PE, phosphatidylethanolamine; DMEM, Dulbecco's modified Eagle's medium.

1 Present address: Instituto Investiqaciones Biologicas, Universidad Nacional Mar del Plata, Casilla de Correo 1245, 7600-Mar del Plata, Argentina.

2 To whom correspondence should be addressed. 
terminal mutations with known $\beta \gamma$-binding properties [12], we have identified additional features in the N-terminus of $\mathrm{G}_{0} \alpha$ that contribute to membrane attachment. These mutant $\mathrm{G}_{0} \alpha$ subunits have been studied by several well-established methods that allow various aspects of membrane binding to be characterized. $G_{0} \alpha$ and mutants were translated in vitro and analysed for interaction with simple lipid vesicles and acceptor membranes prepared from cultured cells. $\mathrm{G} \alpha$ subunits translated in vitro are functional by many criteria, and this technique has been extensively used to study subunit interactions [13] and membrane binding [8,14]. Palmitoylation is a reversible lipid modification that occurs at the plasma membrane, and the non-palmitoylated state of $\mathrm{G} \alpha$ is a critical intermediate during the activation cycle [15-18]. Palmitoylation does not occur during in vitro assays, permitting other contributions to membrane association to be identified [8]. $\mathrm{G}_{0} \alpha$ and each of the mutants were also localized in $\left[{ }^{35} \mathrm{~S}\right]$ methionine- and $\left[{ }^{3} \mathrm{H}\right]$ myristate- or $\left[{ }^{3} \mathrm{H}\right]$ palmitate-labelled transfected COS cells to determine the effects of mutations in the complex environment of an intact cell. Each of the membraneinteraction assays used in these studies offers insight into the range of factors that contribute to the membrane attachment of $\mathrm{G} \alpha$ subunits. Our results suggest that the N-terminal $\alpha$-helix of $\mathrm{G}_{0} \alpha$ is important for membrane binding and that different amino acid regions within the $\mathrm{N}$-terminus may be utilized for protein and/or lipid interactions.

\section{EXPERIMENTAL}

\section{Mutations}

Wild-type rat $\mathrm{G}_{0} \alpha$ cDNA was obtained from Dr. R. R. Reed (Johns Hopkins University, Baltimore, MD, U.S.A.) and all mutations were made by PCR and cloned into Bluescript (Stratagene) as previously described [12]. The D[2-20]E25S mutation [12] was recloned using a $5^{\prime}$ primer to $\mathrm{G}_{0} \propto$ that encoded the $\mathrm{N}$-terminal amino acids shown in Table 1 , and conserved the palmitoylation site at Cys-2. The serine in position 5 is necessary for myristoylation and the alanine at position 6 is also important. These changes had no demonstrable effect on tryptic cleavage patterns or $\beta \gamma$ interactions as previously described [12]. cDNA sequences were confirmed by $\mathrm{T} 7$ doublestranded DNA sequencing (U.S. Biochemical Corp.).

\section{In vitro translation}

cDNAs $(1 \mu \mathrm{g})$ for wild-type or mutant $\mathrm{G}_{\mathrm{o}} \alpha$ in Bluescript were transcribed and translated in vitro (final volume $50 \mu \mathrm{l}$ ) using a coupled reticulocyte lysate system (TNT system; Promega, Madison, WI, U.S.A.) and $\left[{ }^{35}\right.$ S $]$ methionine (Amersham; 20 $\mu \mathrm{Ci} /$ reaction) or $\left[{ }^{3} \mathrm{H}\right]$ myristic acid (Amersham) as previously described [19].

\section{Binding to acceptor membranes}

Binding of in vitro translated $\mathrm{G}_{0} \alpha$ subunits to acceptor membranes was performed under recently described conditions [8]. Briefly, acceptor membranes were prepared from cultured Madin-Darby canine kidney cells by sonication at $4{ }^{\circ} \mathrm{C}$ in buffer A $\left(50 \mathrm{mM}\right.$ Tris/ $\mathrm{HCl}, \mathrm{pH} 7.6,6 \mathrm{mM} \mathrm{MgCl}_{2}, 75 \mathrm{mM}$ sucrose, 1 $\mathrm{mM}$ dithiothreitol (DTT), $1 \mathrm{mM}$ EDTA, $1 \mu \mathrm{g} / \mathrm{ml}$ soya-bean and lima-bean trypsin inhibitors, $3 \mathrm{mM}$ benzamidine) followed by ultracentrifugation at $100000 \mathrm{~g}$ for $1 \mathrm{~h}$ at $4{ }^{\circ} \mathrm{C}$. The particulate fraction was resuspended by sonication in NTE buffer $(10 \mathrm{mM}$ Tris/ $\mathrm{HCl}, \mathrm{pH} 7.4,100 \mathrm{mM} \mathrm{NaCl}, 1 \mathrm{mM}$ EDTA), and the protein concentration determined by Bradford (Bio-Rad). In vitro translated proteins $(2-10 \mu l)$ were incubated with acceptor membranes $(0-4 \mathrm{mg} / \mathrm{ml})$ in NTE and $5 \mu \mathrm{M}$ GDP (final volume $50 \mu \mathrm{l})$ at $25^{\circ} \mathrm{C}$ for $30 \mathrm{~min}$. Soluble and particulate fractions were obtained by ultracentrifugation at $100000 \mathrm{~g}$ and analysed by SDS/PAGE (11\% gels) and autoradiography. Densitometry was performed using a Hewlett-Packard Desk top scanner.

\section{Cross-linking}

The cross-linking reagent 1,6-bis(maleimido)hexane (BMH) was prepared fresh as a $50 \mathrm{mM}$ stock in DMSO. DTT was removed from samples translated in vitro by Sephadex G-50 column

\section{Table 1 -terminal sequences and summary of membrane binding for $G_{0} \alpha$ and mutant subunits}

Each protein is myristoylated both in vitro and in cells (except G1A; N-terminal glycine essential for myristoylation). There is no palmitoylation in acceptor membrane and lipid assays [8], but it does occur in transfected cells on Cys-2. Data for acceptor membrane binding (come from Figure 1$)\left[++\right.$, binding similar to $\mathrm{G}_{0} \alpha(\geqslant 45 \%) ;+$, binding reduced $(20-44 \%) ;-$, not detectable $(<10 \%)$ ], those for lipid vesicle binding (from Figure 4) + , similar to $G_{0} \alpha ;-$, not detectable) and those for cells from Figure 3 [membrane localization in transfected COS cells $(+)$, similar to wild-type $\mathrm{G}_{0} \alpha ;-,<15 \%$ bound]. Intact $\mathrm{G} \beta \gamma$ binding means that a stable heterotrimer is formed on sucrose-density gradients; reduced means that it sediments as a monomer on sucrosedensity gradients, but interaction is detectable with the more sensitive ADP-ribosylation assay [12]; none means that no interaction is detected by either assay. D[3-21] conserves palmitoylation site (Cys-2), and has point mutations in 24 and 25 to preserve myristoylation signal sequence. nd, Not performed.

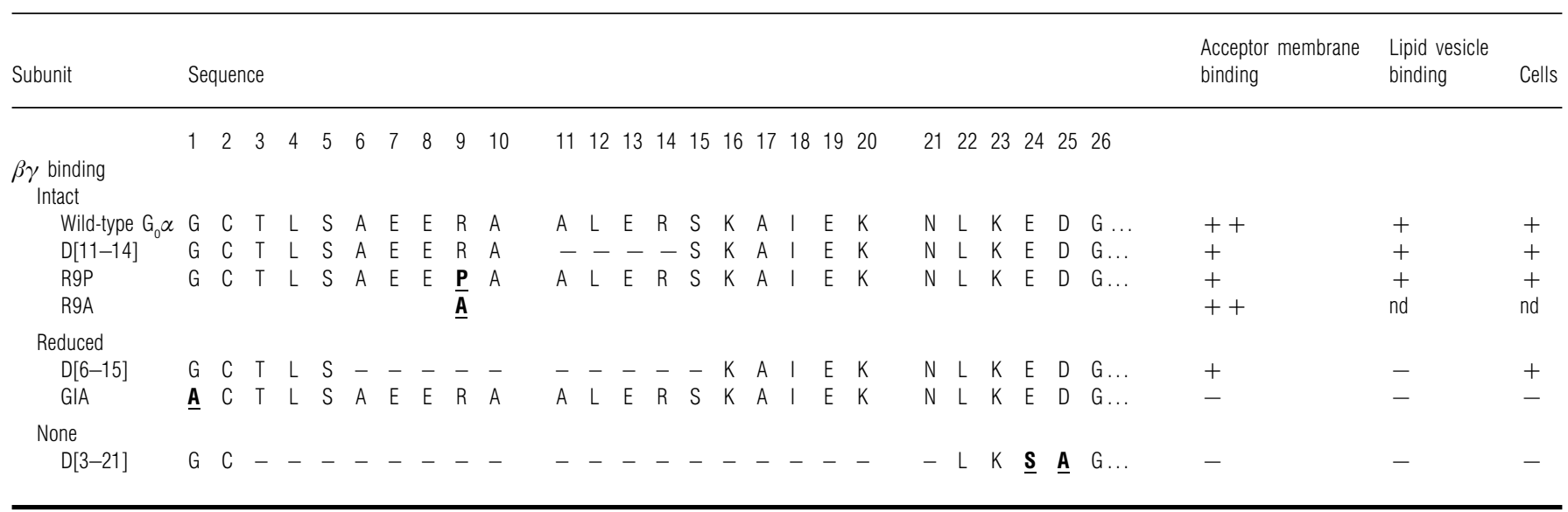


chromatography. Columns $(1 \mathrm{ml})$ were equilibrated with $50 \mathrm{mM}$ Hepes, $\mathrm{pH} 8,6 \mathrm{mM} \mathrm{MgCl}, 75 \mathrm{mM}$ sucrose, $1 \mathrm{mM}$ EDTA and $0.1 \%$ Triton X-100 (buffer C). $\mathrm{G}_{0} \propto$ was cross-linked directly in lysate, or after incubation with acceptor membranes. The pellet fraction obtained by centrifugation at $100000 \boldsymbol{g}$ was resuspended in $20 \mu \mathrm{l}$ of buffer C. All samples were cross-linked in $2 \mathrm{mM} \mathrm{BMH}$ on ice for $20 \mathrm{~min}$ and then quenched by the addition of DTT (final $20 \mathrm{mM}$ ). Control samples included DTT before the addition of BMH. Samples were analysed by SDS/PAGE and autoradiography as described above.

\section{Sucrose-density-gradient centrifugation}

Sucrose-density gradients $(5-20 \%)$ were prepared in $50 \mathrm{mM}$ Tris/ $\mathrm{HCl}, \mathrm{pH} 7.6$, containing $1 \mathrm{mM}$ EDTA, $1 \mathrm{mM}$ DTT, $0.3 \%$ Triton X-100, $1 \mathrm{mM} \mathrm{MgCl}_{2}$ and $100 \mu \mathrm{M}$ GDP or $20 \mu \mathrm{M}$ GTP[S]. Samples of in vitro translated $\mathrm{G} \alpha$ subunits $(30-40 \mu \mathrm{l})$ were mixed with purified $\mathrm{G}_{0} \alpha(0.5 \mu \mathrm{g})$ and $\beta \gamma(1 \mu \mathrm{g})$ from bovine brain (courtesy of E. Neer, Harvard Medical School, Boston, MA, U.S.A.) and incubated with either GDP or GTP[S] for $15 \mathrm{~min}$ at $30^{\circ} \mathrm{C}$. Markers were added [100 $\mu \mathrm{g}$ of BSA, $\left(s_{20, w}=4.3\right)$, ovalbumin $\left(s_{20, w}=3.5\right)$ and carbonic anhydrase $\left.\left(s_{20, w}=2.9\right)\right]$, and the mixture was centrifuged at $80000 \mathrm{~g}(38000 \mathrm{rev} . / \mathrm{min})$ for $20 \mathrm{~h}$ at $4{ }^{\circ} \mathrm{C}$ as previously described [20]. Gradient fractions were analysed by SDS/PAGE as described above. Positions of the peaks of marker proteins and radiolabelled proteins were determined by laser densitometry of autoradiograms or of the stained gels.

\section{Transient transfections}

Each cDNA listed in Table 1 was excised from Bluescript and cloned into eukaryotic expression vector pcDNA 3 (Invitrogen) using HindIII-XbaI or Xbal-ApaI sites depending on the orientation in Bluescript. COS cells were maintained in Dulbecco's modified Eagle's medium (DMEM) with 10\% fetal calf serum and when $50-80 \%$ confluent were transfected in P-60 dishes with $4 \mu \mathrm{g}$ of DNA using LipofectAMINE ${ }^{\bowtie}$ (Gibco-BRL). Cells were incubated with the DNA for $3 \mathrm{~h}$ in serum-free Opti-MEM I (Gibco-BRL). Fetal bovine serum was added to a final concentration of $4 \%$ and the incubation was continued for a total time of $24 \mathrm{~h}$. The cells were washed with fresh medium and kept in DMEM containing $10 \%$ fetal bovine serum until analysis at $48-72 \mathrm{~h}$.

\section{Metabolic labelling, subcellular fractionation and immunoprecipitation}

With minor modifications, transiently transfected COS cells were labelled and analysed as previously described [8]. For ${ }^{35} \mathrm{~S}$ labelling, transfected COS-7 cells were incubated for $30 \mathrm{~min}$ in methionine- and cysteine-free medium. Trans ${ }^{35} \mathrm{~S}-\mathrm{label}{ }^{\circledR}(>1000$ $\mathrm{Ci} / \mathrm{mmol}$; ICN Radiochemicals) was added to a final concentration of $200 \mu \mathrm{Ci} / \mathrm{ml}$ and cells were incubated for $3 \mathrm{~h}$. For labelling with $\left[{ }^{3} \mathrm{H}\right]$ myristic acid, cells were incubated with $[9,10$ $\left.{ }^{3} \mathrm{H}(\mathrm{n})\right]$ myristic acid $(53 \mathrm{Ci} / \mathrm{mmol}$; Amersham Life Science) for 16 $\mathrm{h}$ with $200 \mu \mathrm{Ci} / \mathrm{ml}$ in DMEM $+10 \%$ FBS. For $\left[{ }^{3} \mathrm{H}\right]$ palmitic acid labelling, the cells were incubated in serum-free DMEM for $2 \mathrm{~h}$ followed by $30 \mathrm{~min}$ in $50 \mu \mathrm{g} / \mathrm{ml}$ cycloheximide (Calbiochem) in serum-free medium. Cycloheximide prevents protein synthesis and co-translational myristoylation. $\left[{ }^{3} \mathrm{H}\right] \mathrm{Palmitate}$ labelling was carried out for $30 \mathrm{~min}$ with $500 \mu \mathrm{Ci} / \mathrm{ml}\left[{ }^{3} \mathrm{H}\right]$ palmitic acid $([9,10$ $\left.-{ }^{3} \mathrm{H}(\mathrm{n})\right]$ palmitate $52 \mathrm{Ci} / \mathrm{mmol}$; Amersham) and $50 \mu \mathrm{g} / \mathrm{ml}$ cycloheximide. Cells were washed, resuspended in $500 \mu \mathrm{l}$ of buffer A, frozen and thawed three times in liquid nitrogen and passed 15 times through a 27 -gauge needle. The homogenates were ultracentrifuged at $100000 \mathrm{~g}$ for $1 \mathrm{~h}$ at $4{ }^{\circ} \mathrm{C}$ to prepare soluble and particulate fractions. Immunoprecipitations were carried out in buffer B (10 mM Tris $/ \mathrm{HCl}, \mathrm{pH} 7.4,1 \%$ Triton X-100, $0.1 \%$ SDS, $1 \%$ sodium deoxycholate) after preclearing with Protein A-Sepharose (Sigma). A 1:100 dilution of a polyclonal rabbit antiserum to $G_{0} \propto$ (R4; gift from E. Neer) was added overnight at $4{ }^{\circ} \mathrm{C}$. Protein A-Sepharose was added for $1 \mathrm{~h}$, the samples were centrifuged, and the pellets washed extensively with buffer $\mathrm{B}$. The immunoprecipitates were eluted with SDS/PAGE sample buffer containing either $5 \mathrm{mM}$ DTT (for $\left[{ }^{3} \mathrm{H}\right]$ palmitate-labelled samples) or $50 \mathrm{mM}$ DTT (all others). Immunoprecipitated proteins were analysed by SDS/PAGE and autoradiography as described above.

\section{Binding to liposomes}

Liposomes were prepared by sonication of phospholipid in NTE buffer containing $0.2 \mathrm{M}$ sucrose [21]. Three different compositions of liposomes (Avanti Polar Lipids) were prepared: (1) phosphatidylcholine (PC) alone $(16.2 \mathrm{mg} / \mathrm{ml})$, (2) PC/ phosphatidylethanolamine (PC/PE) $3: 1 \quad(12 \mathrm{mg} / \mathrm{ml} \mathrm{PC}: 4.2$ $\mathrm{mg} / \mathrm{ml} \mathrm{PE}$ ), and (3) phosphatidylserine (PS)/PC 3:1 (12 mg/ml $\mathrm{PS}: 4 \mathrm{mg} / \mathrm{ml} \mathrm{PC}) . \mathrm{G}_{0} \alpha$ and mutant proteins translated in vitro $(2-10 \mu \mathrm{l})$ were incubated with liposomes $(17.5 \mu \mathrm{l})$ in NTE (final volume $50 \mu \mathrm{l})$ plus GTP[S] or GDP $(5 \mu \mathrm{M})$ at $25^{\circ} \mathrm{C}$ for $30 \mathrm{~min}$ in a $0.5 \mathrm{ml}$ Eppendorf tube. Interaction of labelled proteins with liposomes was analysed by flotation centrifugation through a Ficoll density gradient [21]. After incubation, $50 \mu \mathrm{l}$ of $25 \%$ Ficoll (Sigma) in NTE buffer was mixed with the sample and 200 $\mu 1$ of $10 \%$ Ficoll in NTE buffer was added on top. NTE $(100 \mu 1)$ was layered on the very top of the gradient. Samples were centrifuged at maximum speed in an Eppendorf centrifuge for 30 min at $4{ }^{\circ} \mathrm{C}$. Increasing the lipid concentration up to fourfold and varying the temperature by $\pm 5^{\circ} \mathrm{C}$ did not significantly affect binding. Fractions of $50 \mu \mathrm{l}$ were collected with an Eppendorf pipette from the top of the gradient and analysed by SDS/PAGE as described above. The liposomes were recovered at the interface between NTE buffer and the $10 \%$ Ficoll layers (fractions 1-3), and unbound proteins remained in the bottom fractions (6-8). Gels were quantified using a PhosphoImager (Molecular Dynamics).

\section{RESULTS}

To define further the nature of interactions between the $\mathrm{N}$ terminus of $\mathrm{G} \alpha$ subunits and the membrane, we studied a series of $\mathrm{N}$-terminal mutations in $\mathrm{G}_{0} \alpha$ (Table 1). Wild-type $\mathrm{G}_{0} \alpha$ and mutants were analysed in vitro and in transiently transfected COS cells for the ability to attach to membranes or to lipid vesicles. The mutations in Table 1 are grouped according to their ability to interact with $\beta \gamma$ subunits since this interaction also contributes to membrane anchoring [7]. Intact $\mathrm{G} \beta \gamma$ binding is defined as nucleotide-dependent and reversible association of the mutant $\mathrm{G}_{0} \alpha$ subunit with purified $\mathrm{G} \beta \gamma$ on sucrose-density gradients. Like wild-type $\mathrm{G}_{0} \alpha, \mathrm{D}[11-14]$, R9P and R9A each sediment with $\mathrm{G} \beta \gamma$ as a heterotrimer in GDP, but as a monomer in GTP[S] ([12] and Table 3). Reduced $\beta \gamma$ binding is defined as the inability to form a stable heterotrimer on sucrose-density gradients, but a $\mathrm{G} \alpha-\beta \gamma$ interaction that is detectable with a more sensitive assay (ADP-ribosylation [12]). The in vitro association of proteins with lipid vesicles and cellular membranes has been extensively used as a technique to characterize protein-membrane interactions [19,21-26], and, using similar techniques, we recently demonstrated that amino acids 11-14 of $\mathrm{G}_{0} \propto$ contribute to membrane binding [8]. 


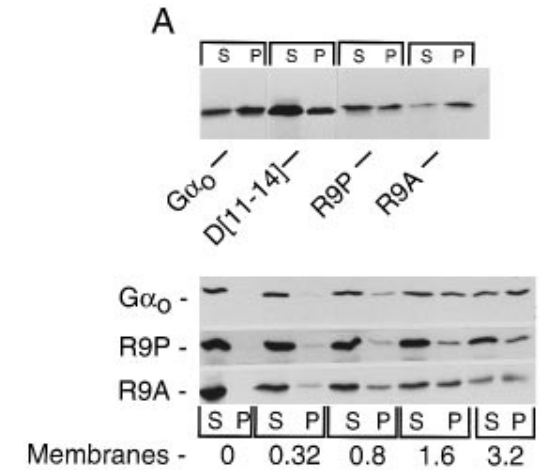

B
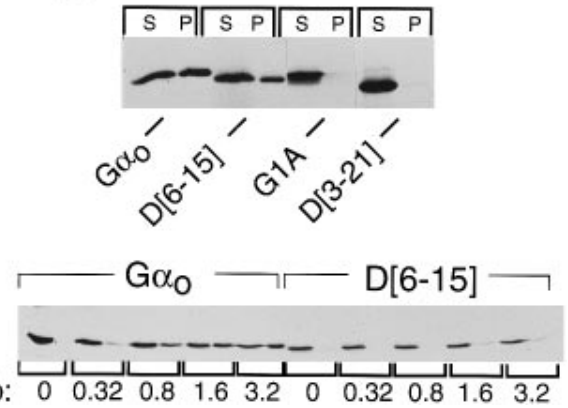

Figure 1 Binding of wild-type $G_{0} \alpha$ and mutants translated in vitro to acceptor membranes

(A) Top, $\mathrm{G}_{0} \alpha$ and mutants with intact $\mathrm{G} \beta \gamma$ binding $\mathrm{D}[11-14]$, R9P, R9A were $\left[{ }^{35}\right.$ S]methioninelabelled and in vitro translated $(5-10 \mu \mathrm{l})$ and incubated with $4 \mathrm{mg} / \mathrm{ml}$ acceptor membranes prepared from Madin-Darby canine kidney cells as described in the Experimental section. Samples were incubated at $30^{\circ} \mathrm{C}$ for $20 \mathrm{~min}$ followed by $100000 \mathrm{~g}$ centrifugation into soluble (S) and particulate (P) fractions and analysed by SDS/PAGE and autoradiography. At similar concentrations of membranes (4-5 mg/ml) binding was $52 \pm 2 \%(n=6)$ for $\mathrm{G}_{0} \alpha, 33 \%$ for $\mathrm{D}\left[11-14\right.$ ] [8], $34 \pm 1 \%(=4)$ for R9P, and $54 \pm 5 \%(n=3)$ for R9A. Bottom, $\mathrm{G}_{0} \alpha$, R9P and R9A binding were compared over a range of acceptor membrane concentrations ( $0-3.2 \mathrm{mg} / \mathrm{ml})$ and analysed as described above. (B) Top, membrane binding of $G_{\alpha} \alpha$ and mutants with reduced or absent $\mathrm{G} \beta \gamma$ interactions. Under conditions similar to those described in $(\mathbf{A})$, mutants were compared with $\mathrm{G}_{0} \alpha$. Binding was $22 \pm 1 \%(n=12)$ for $\mathrm{D}[6-15]$ and $<5 \%$ for G1A and $\mathrm{D}[3-21](n=8)$. Bottom, comparison of membrane binding of $\mathrm{G}_{0} \alpha$ and $\mathrm{D}[6-15]$ over a range of membrane concentrations as described above. Gels were exposed for $24-72 \mathrm{~h}$ at $-70^{\circ} \mathrm{C}$ with two enhancing screens. The autoradiograms were scanned and the density of each band determined by analysis in NIH-Image 1.59/fat (Wayne Rasband, NIH, Bethesda, MD, U.S.A.). The percentage bound was calculated from the equation $[(P$ units $) / S+P$ units $)] \times 100$, and the results for each membrane concentration are given in Table 2 .

\section{Disrupting the $\mathbf{N}$-terminal $\alpha$-helix of $\mathbf{G}_{0} \alpha$ reduces acceptor membrane binding}

Figure 1 compares the acceptor membrane attachment of wildtype $G_{0} \alpha$ and mutant $G_{0} \alpha$ subunits. In the absence of added membranes, each of the in vitro translated proteins was found in the soluble fraction (bottom panels of Figures 1A and 1B), and this is consistent with the absence of aggregation. Figure 1A (top) shows the binding of in vitro translated wild-type $G_{0} \alpha$ subunits and three mutations (D[11-14], R9P and R9A), with intact $\beta \gamma$ binding to $4 \mathrm{mg} / \mathrm{ml}$ acceptor membranes. In comparison with wild-type $\mathrm{G}_{0} \alpha, \mathrm{D}[11-14]$ has reduced acceptor membrane binding, which has recently been characterized [8]. The Arg to Pro point mutant (R9P) also has significantly reduced acceptor membrane binding in comparison with wild-type $\mathrm{G}_{0} \alpha$ [34 $\pm 1 \%(n=4)$ compared with $52 \pm 2 \%(n=6) ; P<0.0002]$. The effect of a mutation at Arg-9 on the acceptor membrane is
Table 2 Summary of acceptor membrane binding to a range of membrane concentrations for $G_{0} \alpha$ and mutants

Binding of in vitro translated $\mathrm{G}_{0} \alpha$ and mutants to increasing amounts of acceptor membrane was as described in the Experimental section and Figure 1. Values are the mean percentage of protein associated with the particulate fraction \pm S.E.M. ( $n=4$ for $\mathrm{G}_{0} \alpha ; n=3$ for R9P) or \pm range for $\mathrm{D}[6-15]$ and R9A $(n=2)$. Autoradiograms were scanned and analysed as described in Figure 1. At each concentration of membrane, the percentage bound was significantly lower for $\mathrm{D}[6-15]$ and $\mathrm{R} 9 \mathrm{P}$ than for $\mathrm{G}_{0} \alpha(P<0.05)$ [except 0 and 0.32 (R9P)].

\begin{tabular}{lrrlll}
\hline \multicolumn{5}{c}{ Binding (\%) } \\
\cline { 2 - 5 } $\begin{array}{l}\text { Membrane concn. } \\
\text { mg/ml... }\end{array}$ & 0 & 0.32 & 0.8 & 1.6 & 3.2 \\
\hline Wild-type $\mathrm{G}_{0} \alpha$ & 0 & $13 \pm 3$ & $28 \pm 3$ & $36 \pm 6$ & $52 \pm 3$ \\
R9P & 0 & $8 \pm 2$ & $10 \pm 2$ & $25 \pm 2$ & $34 \pm 2$ \\
R9A & 0 & $10 \pm 5$ & $21 \pm 5$ & $42 \pm 1$ & $54 \pm 6$ \\
D[6-15] & 0 & $4 \pm 3$ & $11 \pm 10$ & $19 \pm 5$ & $18 \pm 7$ \\
& & & & & \\
\hline
\end{tabular}

\section{Table 3 Sedimentation values of $G_{0} \alpha$ and R9P}

The $S_{20, w}$ values were determined for in vitro translated $\mathrm{G}_{0} \alpha$ and R9P with bovine brain $\beta \gamma$ $(1 \mu \mathrm{g})$ in GDP and GTP[S] as described in the Experimental section. The peak width for each $\mathrm{G}_{0} \alpha$ subunit was similar to the marker proteins, and the $S_{20, w}$ values for wild-type $\mathrm{G}_{0} \alpha$ and are similar to those previously reported [12]. The values are mean \pm range $(n=2)$ or a single value $(n=1)$.

\begin{tabular}{lll}
\hline & \multicolumn{2}{l}{ Sedimentation coefficient $\left[s_{20, w}(\mathrm{~S})\right]$} \\
\cline { 2 - 3 } Mutation & GDP & GTP $[S]$ \\
\hline Wild-type $\mathrm{G}_{0} \alpha$ & 3.5 & $2.9 \pm 0.1$ \\
R9P & $3.6 \pm 0.1$ & 2.4 \\
\hline
\end{tabular}

unique to proline since changing Arg to Ala had no effect on the ability of the mutant protein to interact with acceptor membranes [R9A; $54 \pm 5 \%(n=3)]$. These results were further explored by comparing the binding of R9P and R9A with wild-type $\mathrm{G}_{0} \alpha$ to a range of acceptor membrane concentrations (Figure 1A, bottom; summarized in Table 2). At each membrane concentration, there is no difference between the binding of wildtype $\mathrm{G}_{0} \alpha$ and $\mathrm{R} 9 \mathrm{~A}$, but $\mathrm{R} 9 \mathrm{P}$ is reduced at each concentration tested. This finding is consistent with the idea that disruption of the $\alpha$-helix by proline is sufficient to reduce membrane binding. However, the reduced membrane attachment of R9P is not likely to be occurring through effects on $\beta \gamma$ association, since this mutant reversibly binds $\beta \gamma$-like wild-type $\mathrm{G}_{0} \alpha$ on sucrose-density gradients (Table 3 ).

The mutants (Table 1) with reduced or absent $\beta \gamma$ interactions also show reduced binding to acceptor membranes (Figure 1B, top). Myristoylation of the N-terminal glycine of the $\mathrm{G}_{\mathrm{o}} \alpha$ and $\mathrm{G}_{\mathrm{i}} \propto$ families is necessary for both membrane attachment and intact $\beta \gamma$ interactions [12,27]. All of the proteins in Table 1 are myristoylated in vitro except for G1A (N-terminal glycine is essential for myristoylation). The finding of G1A in the soluble fraction after binding to acceptor membranes is consistent with this observation and was previously reported [8]. However, both $\mathrm{D}[6-15]$ and $\mathrm{D}[3-21]$ are myristoylated yet demonstrate reduced or absent membrane attachment. D[6-15] exhibits reduced $\beta \gamma$ interaction and binds poorly to acceptor membranes (Figure 1B, top; $22 \% \pm 1 ; n=12)$, and $\mathrm{D}[3-21]$ exhibits almost no detectable binding $[<5 \%$; Figure $1 \mathrm{~B},(n=8)]$. Figure $1 \mathrm{~B}$ (bottom) and Table 2 shows that $\mathrm{D}[6-15]$ binding is significantly reduced in comparison with wild-type $\mathrm{G}_{0} \alpha$ over a range of acceptor mem- 

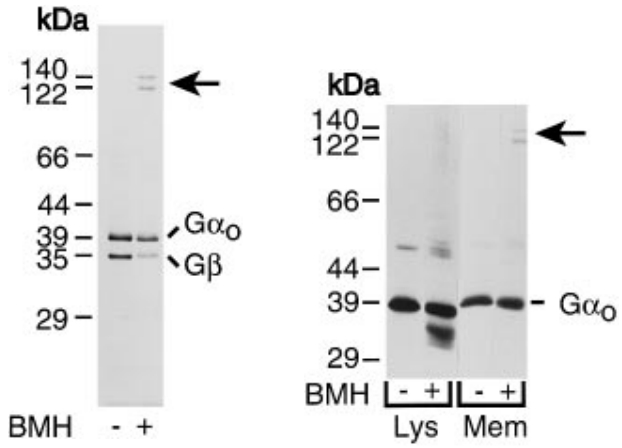

Figure $2 \mathbf{G}_{0} \propto$ translated in vitro can be cross-linked to $\mathbf{G} \beta \gamma$ endogenous to the acceptor membrane

Translated in vitro $\mathrm{G}_{0} \alpha$ was cross-linked after removal of DTT or after binding to acceptor membranes as described in the Experimental section. Samples were incubated with $2 \mathrm{mM} \mathrm{BMH}$ $(+)$ or $20 \mathrm{mM}$ DTT and this was followed by the addition of $2 \mathrm{mM} \mathrm{BMH} \mathrm{(-)} \mathrm{on} \mathrm{ice} \mathrm{for} 20$ min as described in the Experimental section. Samples were analysed by SDS/PAGE and autoradiography as previously described. Left, cross-linked purified bovine brain $G_{0} \alpha \beta \gamma$ is stained with Coomassie Blue. Right, in vitro translated and cross-linked $\mathrm{G}_{0} \alpha$ in lysate (Lys) and after binding to acceptor membranes (Mem). The gel was exposed for 4 days at $-70{ }^{\circ} \mathrm{C}$ with two enhancing screens. The characteristic $\mathrm{G}_{0} \alpha-\beta$ cross-linked bands migrate with apparent molecular masses of 122 and $140 \mathrm{kDa}$ and are marked with the arrow.

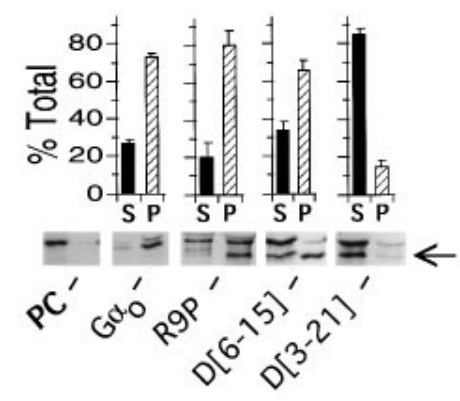

Figure 3 Localization of $G_{0} \alpha, R 9 P, D[6-15]$ and $D[3-21]$ transiently transfected in COS cells

$\mathrm{G}_{0} \alpha$ and mutants in pcDNA $3(4 \mu \mathrm{g})$ were transfected and biosynthetically labelled as described in the Experimental section. All experiments included pcDNA 3 without insert and wild-type $G_{0} \alpha$ as controls. After labelling, cells were scraped, broken and ultracentrifuged at $100000 \boldsymbol{g}$ to yield soluble $(S)$ and particulate $(P)$ fractions. Immunoprecipitations of ${ }^{35} S$ ]labelled $G_{0} \alpha$ and mutants from the soluble and particulate fractions of a representative experiment are shown for each mutant. PC is vector alone control. The $39 \mathrm{kDa}$ size is indicated by the arrow on the right. A background band above $39 \mathrm{kDa}$ was seen in most immunoprecipitations (seen in PC lanes) and varied slightly in distance from the $G_{0} \alpha$ subunit depending on the gel conditions. The results of all experiments are summarized above. The percentage found in the soluble (sold bars) and particulate (hatched bars) fractions were calculated from arbitrary units as described in Figure 1 and are plotted as the mean \pm S.E.M. (except range for R9P where $n=2)\left(n=6\right.$ for $G_{0} \alpha$, $n=5$ for $\mathrm{D}[6-15]$ and $n=5$ for $\mathrm{D}[3-21])$. The reduction in binding was highly significant for $\mathrm{D}[3-21] P<0.006)$, but not significant among the others.

brane concentrations. Membrane-binding results for these mutants do not permit separation of contributions from $\mathrm{G} \beta \gamma$ and $\mathrm{N}$-terminal amino acids, but these results are consistent with contributions of both features to membrane attachment.

\section{$\mathbf{G}_{0} \alpha$ interacts with $\mathbf{G} \beta \gamma$ provided by the acceptor membranes}

Figure 2 demonstrates that endogenous $\beta \gamma$ subunits provided by the acceptor membranes can be cross-linked to in vitro translated $\mathrm{G}_{0} \alpha$ after acceptor membrane binding. $\mathrm{G} \alpha-\beta \gamma$ interactions can be detected through cross-linking of the subunits with BMH. This assay has been extensively used to characterize $\alpha-\beta \gamma$ interactions, and the cysteines that participate in the cross-links have been identified [28-30]. Figure 2 (left) is a Coomassie Bluestained gel of purified $\mathrm{G}_{o} \alpha \beta \gamma$ from bovine brain cross-linked with BMH. The cross-linked products are $\mathrm{G} \alpha-\mathrm{G} \beta$ and are visualized as a doublet at 122 and $140 \mathrm{kDa}$ [28]. The gel on the right of Figure 2 shows $G_{0} \alpha$ translated in vitro and cross-linked in the rabbit reticulocyte lysate (Lys) or after binding to acceptor membranes (Mem). $G_{0} \alpha$ translated in the rabbit reticulocyte lysate and then cross-linked with $\mathrm{BMH}$ fails to form any detectable $\mathrm{G}_{0} \alpha-\beta$ cross-linked products. This indicates that the amount of endogenous $\mathrm{G} \beta \gamma$ present in the rabbit reticulocyte lysate is insufficient to form the expected cross-linked products. However, if cross-linking is performed under identical conditions using the particulate fraction of in vitro translated $\mathrm{G}_{0} \alpha$ bound to acceptor membranes, then there is sufficient endogenous $\mathrm{G} \beta \gamma$ in the acceptor membrane to detect the expected $\mathrm{G}_{0} \alpha-\mathrm{G} \beta$ crosslinked products at 140 and $122 \mathrm{kDa}$. This finding is consistent with previous reports suggesting that $\mathrm{G} \beta \gamma$ can contribute to anchoring of $\mathrm{G}_{0} \alpha$ in the membrane [7].

\section{Differences in myristoylation do not account for reduced membrane interactions}

Since myristoylation is required for membrane binding of $\mathrm{G}_{0} \alpha$ (Figure 1), differences in myristoylation occurring in vitro could account for the reduced membrane binding. However, we have previously demonstrated that myristoylation of $\mathrm{N}$-terminal mutations is not reduced compared with wild-type $\mathrm{G}_{0} \alpha$, and that $\left[{ }^{3} \mathrm{H}\right]$ myristate-labelled $\mathrm{G}_{0} \alpha$ subunits have a similar distribution in the soluble and particulate fractions to the $\left[{ }^{35}\right.$ S]methioninelabelled subunits [8]. To investigate the efficiency of in vitro myristoylation of $\mathrm{D}[6-15]$ and $\mathrm{D}[3-21]$, parallel in vitro translations with $\left[{ }^{35} \mathrm{~S}\right]$ methionine and $\left[{ }^{3} \mathrm{H}\right]$ myristic acid were carried out and the autoradiograms quantified for $\left[{ }^{3} \mathrm{H}\right]$ myristate incorporation as a fraction of $\left[{ }^{35} \mathrm{~S}\right]$ methionine incorporation. The values were normalized to the wild-type control and reveal that $\mathrm{D}[6-15]$ is myristoylated similarly to wild-type $\mathrm{G}_{0} \propto$ [ratio; $1.3 \pm 0.24(n=4)]$. However, myristoylation of $\mathrm{D}[3-21]$ is less efficient than for wild-type $\mathrm{G}_{0} \alpha$ with a ratio of $0.6 \pm 0.1(n=5)$. The reduced myristoylation efficiency of $\mathrm{D}[3-21]$ probably results from amino acid changes in positions 3 and 4 . $N$-Myristoyltransferase peptide specificity has been determined (reviewed in [31]) and occurs over the initial six to eight amino acids (one to five most important). Nevertheless, a significant fraction of $\mathrm{D}[3-21]$ is myristoylated, and the reduced myristoylation efficiency does not account for the absence of detectable interactions with acceptor membranes. These results confirm our previous finding that differences in myristoylation of $\mathrm{G}_{0} \alpha$ and mutants are unlikely to account for variations in membrane attachment.

\section{In transfected COS cells, R9P and D[6-15] are predominantly membrane-associated, but $D[3-21]$ is mostly cytosolic}

We have previously shown that palmitoylation does not occur under the experimental conditions utilized for in vitro studies [8]. Since palmitoylation is reversible, the non-palmitoylated state is important to $\mathrm{G} \alpha$-membrane interactions at different times during the activation cycle. To determine the effects of these mutations on their localization in cells, transient transfections in COS cells were performed. Figure 3 shows subcellular fractionation of $\left[{ }^{35} \mathrm{~S}\right]$ methionine-labelled COS cells transfected with wild-type $\mathrm{G}_{\mathrm{o}} \alpha, \mathrm{R} 9 \mathrm{P}, \mathrm{D}[6-15]$ and $\mathrm{D}[3-21]$. As previously shown [8], about 
Table 4 Fraction of myristoylated or palmitoylated proteins in the particulate fraction of transfected COS cells

Labelling, subcellular fractionation and immunoprecipitation of transfected COS cells were performed as described in the Experimental section. Autoradiograms were exposed for 3-4 weeks and the intensity of the bands quantified as described in Figure 1. Values are the percentage of total signal detected in the particulate fraction \pm the range (when $n=2$ ) or S.D. (when $n=3$ ). For $\mathrm{D}[6-15]$ transfected cells, incorporation of $\left[{ }^{3} \mathrm{H}\right]$ myristate into cell homogenate was detectable, but could not be quantified in the subcellular fractions because of the low signal. All of the $\left[{ }^{3} \mathrm{H}\right]$ myristate signal was found in the soluble fraction, and there was no detectable $\left[{ }^{3} \mathrm{H}\right]$ palmitate labelling in either soluble or particulate fractions for $\mathrm{D}[3-21]$.

\begin{tabular}{lll}
\hline Mutation & $\begin{array}{l}{\left[{ }^{3} \mathrm{H}\right] \text { Myristate }(\mathrm{P})} \\
(\%)\end{array}$ & $\begin{array}{l}{\left[{ }^{3} \mathrm{H}\right] \text { Palmitate }(\mathrm{P})} \\
(\%)\end{array}$ \\
\hline $\mathrm{G}_{0} \alpha$ & $80 \pm 15(n=2)$ & $93 \pm 3(n=3)$ \\
$\mathrm{D}[6-15]$ & - & $92 \pm 5(n=2)$ \\
$\mathrm{D}[3-21]$ & $<5(n=2)$ & $0(n=3)$ \\
\hline
\end{tabular}

$75 \%$ of $\mathrm{G}_{0} \alpha$ is found in the membrane fraction, and both R9P and $\mathrm{D}[6-15]$ are also predominantly membrane-attached in COS cells. The particulate fraction for each of these proteins was $80-90 \%$ Triton X-100-soluble (not shown), indicating that the proteins were not aggregated. There was slightly more D[6-15] in the soluble fraction $(35 \%)$ than for $\mathrm{G}_{0} \alpha(25 \%)$, but this result was not significant. Wild-type $\mathrm{G}_{0} \alpha, \mathrm{D}[6-15]$ and R9P are myristoylated and palmitoylated in COS cells and there is a higher fraction of each in the membranes of COS cells than in acceptor membranes (Figures 3 and 1). The contribution of palmitoylation and other unknown interactions to membrane binding in cells is likely to account for the differences between in vitro and COS cell studies. Since palmitoylation occurs in COS cells, but not in vitro, the finding of R9P predominantly in the membrane (like $\mathrm{G}_{0} \alpha$ ) indicates that both myristoylation and palmitoylation are unaffected. Table 4 summarizes the fraction of $\left[{ }^{3} \mathrm{H}\right]$ myristate- or $\left[{ }^{3} \mathrm{H}\right]$ palmitate-labelled $\mathrm{G}_{0} \alpha, \mathrm{D}[6-15]$ and $\mathrm{D}[3-21]$ in the membrane fraction of transfected COS cells. Quantification is difficult in these assays because of the low specific radioactivity of the ${ }^{3} \mathrm{H}$ label, a single modification site on the protein, and modest levels of expression. Nevertheless, virtually all of the palmitate label is detected in the particulate fraction. It was not possible to determine the fraction of $\left[{ }^{3} \mathrm{H}\right]$ myristate-labelled $\mathrm{D}[6-15]$ in the membrane fraction because of low signal, and we cannot exclude the possibility that the distribution of the myristate-labelled protein is different from the ${ }^{35} \mathrm{~S}$-labelled protein. However, this is unlikely because the myristoylation efficiency of $D[6-15]$ in vitro is similar to $G_{0} \alpha$ (see above), and there was no significant difference between $\mathrm{D}[6-15]$ and $\mathrm{G}_{0} \alpha$ in the amount found in the particulate fraction. Consistent with in vitro results, D[3-21] expressed in COS cells is mostly soluble (Figure 3). The cytosolic localization of D[3-21] in COS cells is somewhat surprising given that $\mathrm{D}[6-15]$ is predominantly membrane attached (Figure 3 ). Although in vitro translated D[3-21] has no detectable interactions with acceptor membranes (Figure 1), it is myristoylated and potentially palmitoylated on Cys-2. Nevertheless, we could detect no palmitoylation of $\mathrm{D}[3-21]$ in transfected COS cells even though expression was confirmed in parallel ${ }^{35} \mathrm{~S}$-labelled cells. $\mathrm{D}[3-21]$ is less efficiently myristoylated than wild-type $G_{0} \alpha$, but all of the myristate label is detected in the soluble fraction (Table 4). This indicates that palmitoylation of $\mathrm{D}[3-21]$ does not occur even on the myristoylated fraction. For palmitoylation to occur, localization in the membrane is required, and myristoylation may not be necessary [15]. This suggests that for $\mathrm{D}[3-21]$ an additional feature(s) necessary for membrane binding is missing.

\section{Lipid vesicle composition influences $\mathbf{G}_{0} \alpha$ lipid interaction and requires myristoylation}

Many complex protein and lipid interactions potentially affect the membrane binding of $\mathrm{G} \alpha$ subunits. To gain further insights into the nature of the interactions of $\mathrm{G}_{0} \alpha$ with the membrane, we characterized the interaction of $\mathrm{G}_{0} \alpha$ and mutants with unilamellar lipid vesicles. We used the methods (described in the Experimental section) that have been described for the characterization of transducin $\alpha\left(\mathrm{G}_{t} \alpha\right)$ with a variety of lipid membranes [21]. In vitro translated $\mathrm{G}_{0} \alpha$ was incubated with several liposome mixtures and analysed on Ficoll gradients in the presence of $5 \mu \mathrm{M}$ GDP or GTP[S]. The lipid vesicle binding of $\mathrm{G}_{0} \alpha$ was similar in the GDP- and GTP[S]-liganded conformations (not shown). Liposomes and unbound protein are separated on the gradient according to differences in density. Figure 4A (top row) shows that, in the absence of added liposomes, in vitro translated $\mathrm{G}_{0} \alpha$ sediments to the bottom of the gradient (fractions 6-8). After incubation with PC liposomes, $23 \pm 1 \%(n=16)$ of $\mathrm{G}_{0} \alpha$ is found at the top of the gradient (fractions 1-3) associated with the lessdense liposomes (Figure 4A). In contrast, binding of $G_{0} \alpha$ to predominantly negatively charged phospholipid vesicles $(75 \%$ PC: $25 \%$ PC) was significantly reduced $(9 \pm 1 \%(n=9) ; P<$ 0.05 ) (Figure 4A). Results with PE lipid vesicles (neutral) were similar to those with PC vesicles (not shown). The fraction of in vitro translated $G_{0} \alpha$ binding to lipid vesicles is similar to the amount seen with purified $G_{t} \alpha$ [21]. Furthermore, myristoylation itself is not sufficient for complete liposome binding. Studies of liposome binding with myristoylated N-terminal peptides to Src showed synergistic binding when myristate was incorporated on peptides containing positively charged amino acids [32]. The components required for full liposome interactions of $\mathrm{G} \alpha$ are likely to include $\mathrm{G} \beta \gamma$, other membrane proteins, lipid heterogeneity and palmitate (each of which would be expected to enhance lipid binding). Similarly to results with other assays of membrane association, myristoylation is also necessary for interactions with phospholipid vesicles. Figure 4A shows that there is no detectable interaction of G1A (non-myristoylated $\mathrm{G}_{0} \alpha$ ) with lipid vesicles. The relatively low fraction of ${ }^{35} \mathrm{~S}$-labelled $\mathrm{G}_{0} \alpha$ binding to liposomes could also be explained by in vitro myristoylation of a subpopulation of $\mathrm{G}_{0} \alpha$. To exclude this possibility, $\left[{ }^{3} \mathrm{H}\right]$ myristate-labelled $\mathrm{G}_{0} \alpha$ was incubated with PC liposomes and analysed as previously described. Figure 4(B) shows that the distribution of $\left[{ }^{3} \mathrm{H}\right]$ myristate-labelled $\mathrm{G}_{0} \alpha$ along the Ficoll gradient is similar to that seen using $\left[{ }^{35} \mathrm{~S}\right]$ methioninelabelled protein (Figure 4A). This indicates that the $\mathrm{G}_{0} \alpha$ bound to liposomes is not simply the myristoylated population.

\section{R9P and $D[11-14]$ bind to $P C$ vesicles like wild-type $G_{0} \alpha$, but $D[6-15]$ and $D[3-21]$ exhibit almost no detectable interaction}

The mutants in Table 1 were translated in vitro and analysed for association with PC liposomes (Figure 4C) as described above. None of the mutant proteins are found in the top of the gradient in the absence of liposomes (not shown). Each mutant $\mathrm{G}_{0} \alpha$ subunit is myristoylated (discussed above), and both $\mathrm{D}[11-14]$ and R9P interact with liposomes like wild-type $\mathrm{G}_{0} \alpha$. However, the longer deletions, $\mathrm{D}[6-15]$ and $\mathrm{D}[3-21]$, exhibit almost no detectable interaction with lipid vesicles. $\mathrm{D}[6-15]$ is myristoylated like wild-type $G_{0} \alpha$, so this is not likely to account for the significantly reduced lipid binding. Comparison of the amino 

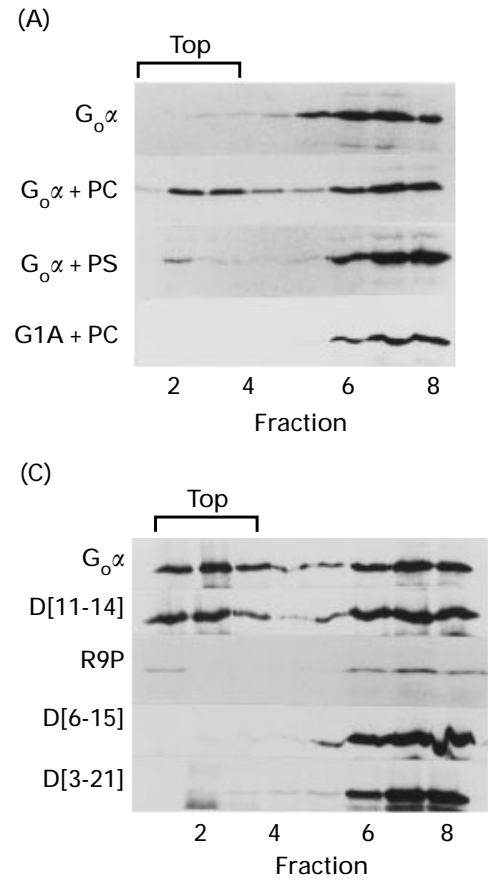

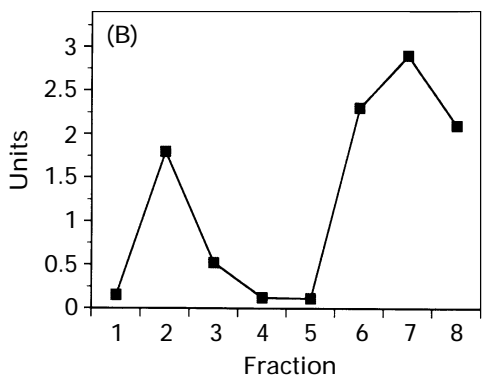

Fraction

Figure 4 Association of in vitro translated $G_{0} \alpha$ and mutants with phospholipid vesicles

In vitro translated, ${ }^{35} \mathrm{~S}$-labelled $\mathrm{G}_{0} \alpha$ and mutants were incubated with and without liposomes of different composition followed by analysis on Ficoll gradients as described in the Experimental section. (A) Gradient profiles for $G_{0} \alpha$ in the absence of added liposomes (1st row), and after incubation with PC liposomes $\left(G_{0} \alpha+P C\right.$; row 2$)$, incubation with predominantly PS (75\%) vesicles ( $G_{0} \alpha+P S$; row 3), and binding of non-myristoylated mutant, G1A + PC (row 4). Liposomes are found in fractions 1-3 near the top of the gradient whereas unbound protein remains at the bottom of the gradient (fractions 6-8). The percentage bound to lipid vesicles was calculated from arbitrary units obtained from scanned autoradiograms as described in Figure 1. The total in fractions $1-3$ was considered 'bound' and this was divided by the total number of arbitrary units in 1-8 to obtain the percentage bound. In the absence of added liposomes, the amount of $\mathrm{G}_{0} \alpha$ found in fractions $1-3$ was less than $5 \%(n=4)$. $\mathrm{G}_{0} \alpha-P C$ binding was $23 \% \pm 1(n=14)$, and for $\mathrm{G}_{0} \alpha-P S$ was $9 \pm 1(n=9)$. The difference in $\mathrm{G}_{0} \alpha$ binding to $P C$ versus PS liposomes was significant $(P<0.05)$. (B) Densitometry tracing of $\left[{ }^{3} \mathrm{H}\right]$ myristate-labelled $\mathrm{G}_{0} \alpha$ to $\mathrm{PC}$ vesicles. $\mathrm{G}_{0} \alpha$ was translated in vitro with unlabelled methionine and $\left[{ }^{3} \mathrm{H}\right] \mathrm{myristic}$ acid as described in the Experimental section. $\left[{ }^{3} \mathrm{H}\right]$ myristate-labelled $\mathrm{G}_{0} \alpha$ was incubated with $\mathrm{PC}$ vesicles and analysed as described. The autoradiogram was exposed for 65 days, scanned and analysed as described above. Arbitrary units obtained from scanned data were plotted against fraction number and plotted in Deltagraph Pro (Monterey, CA, U.S.A.). (C) Comparison of PC lipid binding for G $\alpha$, D[11-14], R9P, D[6-15] and $\mathrm{D}[3-21]$. The percentage binding was $21 \pm 2(n=8)$ for $\mathrm{D}[11-14], 21 \pm 1(n=3)$ for R9P, $4 \pm 1(n=7)$ for $\mathrm{D}[6-15]$, and $5 \pm 1(n=3)$ for $\mathrm{D}[3-21]$.

acid sequences of D[11-14] (normal lipid binding) and D[6-15] (almost absent lipid binding) (summarized in Table 1) suggest that deleting the additional amino acids $(6-10,15)$ significantly affects interaction with liposomes.

\section{DISCUSSION}

Our analysis of $\mathrm{G}_{\mathrm{o}} \propto$ mutants grouped according to their ability to interact with $\mathrm{G} \beta \gamma$ allows us to extend our understanding of the role that the $\mathrm{N}$-terminus plays in membrane attachment of $\mathrm{G} \alpha$ subunits. The mutants in this study were analysed using different assays that permit partial segregation of the variables that contribute to membrane binding. Unilamellar vesicles are the simplest artificial membranes and allow interactions of $\mathrm{G}_{0} \alpha$ with lipids to be studied without the complicating contributions from other membrane proteins and $\beta \gamma$. In vitro acceptor membranes are more complex and include endogenous proteins (such as $\beta \gamma$ ) and heterogeneous lipids that can contribute to membrane binding. Finally, we localized several of these mutants in COS cells where complexity is maximal.

Using a similar approach, we have previously shown that amino acids $11-14$ of $\mathrm{G}_{0} \alpha$ contribute to membrane attachment in addition to myristoylation, palmitoylation and $\beta \gamma$ interactions [8]. We now demonstrate that disturbing the $\alpha$-helix of $\mathrm{G}_{0} \alpha$ with a proline point mutation (R9P) also disrupts membrane attachment. Like D[11-14], R9P binds $\beta \gamma$ normally on sucrose- density gradients and is identical in length with wild-type $G_{0} \alpha$. Despite reduced acceptor membrane binding, R9P binds like wild-type $\mathrm{G}_{0} \propto$ to lipid vesicles, indicating that differences in myristoylation or changes in the orientation of the myristate group are not likely to account for the reduced binding to acceptor membranes. The acceptor and liposome binding assay reveal different aspects of $\mathrm{G} \alpha$-membrane interactions. The acceptor membranes are a mixture of proteins (including $\mathrm{G} \beta \gamma$; Figure 2) and lipids from cellular membranes, and the purified liposomes are devoid of proteins and lipid heterogeneity. Although the liposomes may not accurately reflect the lipid environment within the plasma membrane, the assay permits the effects of lipids on $\mathrm{G} \alpha$ interactions to be characterized. The binding characteristics of R9P [reduced to acceptor membranes, but intact to lipids (summarized in Table 1)] raise the possibility that the $\mathrm{N}$-terminus of $\mathrm{G}_{0} \propto$ interacts with another protein in the acceptor membrane. Furthermore D[11-14] exhibits nearly identical membrane binding to R9P (see Table 1). Taken together, these results suggest that a membrane protein may be involved in stabilizing $G_{0} \alpha$ in the membrane which is partially disrupted by changing the $\alpha$-helix (R9P) or deleting amino acids 11-14 (D[11-14]). Alternatively, these mutations could affect the orientation of the myristate group or another amino acid region that affects binding to acceptor membranes. Both D[11-14] and R9P bind normally to lipids and exhibit intact $\beta \gamma$ binding; this supports the possibility that some other protein(s) is responsible 
for the interaction. Although this analysis is indirect, there are many studies suggesting that G-proteins are part of highmolecular-mass signalling complexes [20,33-39].

It is difficult to separate the various factors contributing to membrane attachment when localization is studied by transient transfection assays. The predominant membrane attachment of $\mathrm{D}[6-15]$ and $\mathrm{R} 9 \mathrm{P}$ in transfected cells was expected. We have previously shown that it is necessary to block palmitoylation to appreciate the contribution of N-terminal amino acids to membrane attachment in COS cells [8]. The non-palmitoylated state is a critical intermediate during the cycle of $\mathrm{G} \alpha$ activation when other structural features are likely to be important for maintaining association with the membrane. Although in vitro translated $\mathrm{D}[3-21]$ did not bind to acceptor membranes, this did not necessarily predict a similar result in COS cells. D[3-21] is myristoylated and preserves the palmitoylation site on Cys-2, which may have permitted membrane association. However, $D[3-21]$ was almost completely soluble in COS cells and was not palmitoylated. Since membrane localization may be necessary for palmitoylation to occur [15], the shortened N-terminus disrupted important membrane-binding regions or affected targeting to the membrane. Other factors that could also contribute to the cytosolic localization of $\mathrm{D}[3-21]$ include the absence of $\beta \gamma$ interactions, altered substrate specificity for palmitoyltransferase, or deletion of a membrane targeting sequence. In the yeast $\mathrm{G} \alpha$ subunit, Gpa1, myristoylation appears to be part of a targeting sequence necessary for localization in the plasma membrane [40]. Our results with $\mathrm{D}[3-21] \alpha_{0}$ raise the possibility that, in addition to myristoylation, other $\mathrm{N}$-terminal sequence(s) contribute to membrane binding or may be required for targeting to the plasma membrane.

There is increasing evidence that the distribution of G-proteins in the plasma membrane is not random (reviewed in [1]), and the mechanisms that maintain signalling molecules within discrete domains are unknown. One possible explanation is that interactions between $\mathrm{G} \alpha$ and membrane lipids influence protein mobility within the plasma membrane. There are many different lipid moieties in the plasma membrane of cells (reviewed in [41]), and polarized epithelia cells have distinct lipid compositions within the apical and basolateral membranes (reviewed in [42]). G-proteins and G-protein-coupled receptors have been localized to specific membrane domains [43-48] and in caveolae (unique plasma-membrane domains) [49]. We found that changing the composition of lipid vesicles affects $G_{0} \alpha$ interactions. $G_{0} \alpha$ binds more readily to neutral (PC or PE) lipids than to negatively charged (PS) lipids, and this may result from the net negative charge within the $\mathrm{N}$-terminus of $\mathrm{G}_{0} \alpha$ (Table 1). This is in contrast with transducin $\alpha$, which preferentially binds to negatively charged lipid vesicles [21]. These observations are consistent with the idea that lipid interactions within the plasma membrane may affect membrane localization and/or affinity for the membrane. Furthermore the results of phospholipid binding with mutant $\mathrm{G}_{0} \propto$ subunits reveal that myristoylation is necessary but not sufficient for these interactions. Extending the N-terminal deletion from amino acids 11-14 to 6-15 causes complete loss of liposome interactions. This finding could be explained by a critical length of the N-terminus or possibly through direct interaction of amino acids 6-10 in liposome binding. Alternatively, the result could also arise indirectly through effects of the deletion on the orientation of the myristate group. The orientation of the myristate group would be expected to be altered in R9P, yet this protein interacts with lipid vesicles like wild-type $\mathrm{G}_{0} \alpha$. These possibilities cannot be distinguished at this time, but the results clearly identify the importance of the N-terminus in addition to myristoylation for binding to lipid vesicles.
These studies reveal additional complexity of the $\mathrm{N}$-terminus in membrane attachment of $\mathrm{G} \alpha$ subunits. In addition to previously recognized factors, these results suggest the existence of unique interactions with membrane protein(s) and lipids that may be important for anchoring and localizing G-proteins into specific membrane regions. Other features may also be important; the affinity of $\mathrm{G}_{\mathrm{z}} \alpha$ and $\mathrm{G}_{12} \alpha$ for $\mathrm{G} \beta \gamma$ is significantly reduced by phosphorylation on serine residues in the $\mathrm{N}$-terminus [50,51], although it is not known if membrane association is affected by phosphorylation. The relative contributions from different $\mathrm{N}$ terminal features to membrane attachment is likely to vary among $\mathrm{G} \alpha$ subunits and depend upon the state of activation. The membrane localization of $\mathrm{G} \alpha$ subunits and the mechanisms of membrane attachment are critical for rapid, reversible and accurate interactions with other molecules during the cycle of receptor activation. Each aspect of the membrane interaction provides an opportunity for regulation that may contribute to signal specificity. Future studies will focus on the role of the Nterminus in regulation of signalling specificity through interactions of the $\mathrm{N}$-terminus with components of the plasma membrane.

We thank Dr. E. Neer for her helpful comments and suggestions and to Paula Boutin for her expert technical assistance. This work was supported by National Institutes of Health Grants Clinical Investigator Award DK02110, National Kidney Foundation Young Investigator Grant, and American Heart Association (Massachusetts Affiliate) Beginning Grant in Aid (to B.M.D.).

\section{REFERENCES}

1 Neer, E. J. (1995) Cell 80, 249-257

2 Bourne, H. R., Sanders, D. A. and McCormick, F. (1990) Nature (London) 348 125-131

3 Bourne, H. R., Sanders, D. A. and McCormick, F. (1991) Nature (London) $\mathbf{3 4 9}$, 117-127

4 Wedegaertner, P. B., Wilson, P. T. and Bourne, H. R. (1995) J. Biol. Chem. 270 503-506

5 Lambright, D. G., Sondek, J., Bohm, A., Skiba, N. P., Hamm, H. E. and Sigler, P. B. (1996) Nature (London) 379, 311-319

6 Wall, M. A., Coleman, D. E., Lee, E., Iniguez-Lluhl, J. A., Posner, B. A., Gilman, A. G. and Sprang, S. R. (1995) Cell 83, 1047-1058

7 Sternweis, P. (1986) J. Biol. Chem. 261, 631-637

8 Busconi, L., Boutin, P. M. and Denker, B. M. (1997) Biochem J. 323, 239-244

9 Noel, J. P., Hamm, H. E. and Sigler, P. B. (1993) Nature (London) 366, 654-663

10 Mixon, M., Lee, E., Coleman, D. E., Berghuis, A. M., Gilman, A. G. and Sprang, S. R. (1995) Science 270, 954-960

11 Coleman, D. E., Berghuis, A. M., Lee, E., Linder, M. E., Gilman, A. G. and Sprang, S. R. (1994) Science 265, 1405-1412

12 Denker, B. M., Neer, E. J. and Schmidt, C. J. (1992) J. Biol. Chem. 267, 6272-6277

13 Neer, E. J., Denker, B. M., Thomas, T. C. and Schmidt, C. J. (1994) Methods Enzymol. 237, 226-239

14 Denker, B. M., Boutin, P. M. and Neer, E. J. (1995) Biochemistry 34, 5544-5553

15 Degtyarev, M. Y., Spiegel, A. M. and Jones, T. L. Z. (1994) J. Biol. Chem. 269 30898-30903

16 Wedegaertner, P. B., Chu, D. H., Wilson, P. T., Levis, M. J. and Bourne, H. R. (1993) J. Biol. Chem. 268, 25001-25008

17 Wedegaertner, P. B. and Bourne, H. R. (1994) Cell 77, 1063-1070

18 Mumby, S. M., Kleuss, C. and Gilman, A. G. (1994) Proc. Natl. Acad. Sci. U.S.A. 91, 2800-2804

19 Busconi, L. and Michel, T. (1994) J. Biol. Chem. 269, 25016-25020

20 Denker, B. M. and Neer, E. J. (1991) FEBS Lett. 279, 98-100

21 Matsuda, T., Takao, T., Shimonishi, Y., Murata, M., Asano, T., Yoshizawa, T. and Fukada, Y. (1994) J. Biol. Chem. 269, 30358-30363

22 Silverman, L. and Resh, M. D. (1992) J. Cell Biol. 119, 415-425

23 Resh, M. (1989) Cell 58, 281-286

24 George, D. J. and Blackshear, P. J. (1992) J. Biol. Chem. 267, 24879-24885

25 Haun, R. S., Su-Chen, T., Adamik, R., Moss, J. and Vaughan, M. (1993) J. Biol. Chem. 268, 7064-7068

26 Ladant, D. L. (1995) J. Biol. Chem. 270, 3179-3185

27 Linder, M. E., Pang, I., Durino, R. J., Gordon, J. I., Sternweis, P. C. and Gilman, A. G. (1991) J. Biol. Chem. 266, 4654-4659

28 Yi, F., Denker, B. M. and Neer, E. J. (1991) J. Biol. Chem. 266, 3900-3906 
29 Thomas, T. C., Schmidt, C. J. and Neer, E. J. (1993) Proc. Natl. Acad. Sci U.S.A. 90 10295-10299

30 Garcia-Higuera, I., Thomas, C. T., Yi, F. and Neer, E. J. (1996) J. Biol. Chem. 271 528-535

31 Towler, D. A., Gordon, J. L., Adams, S. P. and Glaser, L. (1988) Annu. Rev. Biochem. 57, 69-99

32 Buser, C. A., Sigal, C. T., Resh, M. D. and McLaughlin, S. (1994) Biochemistry 33 13093-13101

33 Sahyoun, N. E., Levine, III, H., Davis, J., Hebdon, G. M. and Cuatrecasas, P. (1981) Proc. Natl. Acad. Sci. U.S.A. 78, 6158-6162

34 Cherksey, B. D., Zadunaisky, J. A. and Murphy, R. B. (1980) Proc. Natl. Acad. Sci. U.S.A. 77, 6401-6405

35 Insel, P. A. and Kennedy, M. S. (1978) Nature 273, 471-472

36 Janangeer, S. and Rodbell, M. (1993) Proc. Natl. Acad. Sci. U.S.A. 90, 8782-8786

37 Nakamura, S. and Rodbell, M. (1990) Proc. Natl. Acad. Sci. U.S.A. 87, 6413-6417

38 lanobe, A., Takahashi, K. and Katada, T. (1994) J. Biochem. (Tokyo) 115, 486-492

39 Ibarrondo, J., Joubert, D., Dufour, M. N., Cohen-Solal, A., Homburger, V., Jard, S. and Guillon, G. (1995) Proc. Natl. Acad. Sci. U.S.A. 92, 8413-8417
40 Song, J., Hirschman, J., Gunn, K. and Dohlman, H. G. (1996) J. Biol. Chem. 271, 20273-20283

41 Allan, D. (1996) Mol. Memb. Biol. 13, 81-84

42 Simons, K. and van Meer, G. (1988) Biochemistry 27, 6197-6202

43 Stow, J. L., Sabolic, I. and Brown, D. (1991) Am. J. Physiol. 261, F831-F840

44 Saunders, C., Keefer, J. R., Kennedy, A. P., Wells, J. N. and Limbird, L. E. (1996) J. Biol. Chem. 271, 995-1002

45 Brunskill, N., Bastani, B., Hayes, C., Morrissey, J. and Klahr, S. (1991) Kidney Int. 40, 997-1006

46 Ercolani, L., Stow, J. L., Boyle, J. F., Holtzman, E. J., Lin, H., Grove, J. R. and Ausiello, D. A. (1990) Proc. Natl. Acad. Sci. U.S.A. 87, 4637-4639

47 de Almeida, J. B., Holtzman, E. J., Peters, P., Ercolani, L., Ausiello, D. A. and Stow, J. L. (1994) J. Cell Sci. 107, 507-515

48 Denker, B. M., Saha, C., Khawaja, S. and Nigam, S. J. (1996) J. Biol. Chem. 271, 25750-25753

49 Sargiacomo, M., Sudol, M., Tang, Z. and Lisanti, M. P. (1993) J. Cell Biol. 122, 789-807

50 Fields, T. A. and Casey, P. J. (1995) J. Biol. Chem. 270, 23119-23125

51 Kozasa, T. and Gilman, A. G. (1996) J. Biol. Chem. 271, 12562-12567

Received 12 March 1997/9 July 1997; accepted 21 July 1997 